\title{
THE LONGITUDINAL STRESS AND STRAIN-RATE GRADIENTS IN ICE MASSES
}

\author{
Ey W. F. Budd \\ Antarctic Division, Department of Supply, 568 St Kilda Road, Melbourne, Victoria 3004 , \\ Australia)
}

\begin{abstract}
Aвstract. The fundamental equation for the longitudinal stress and strain-rate gradient for ice masses with small slope (Budd, 1968) has been derived exactly for any slope by Nye (1969) who shows that by using a variable longitudinal axis inclination, parallel to the surface, this equation takes on its simplest form. However for the integration of this equation along the ice mass to obtain stress and strain-rates it is necessary to use a fixed axis direction. Here the equation is derived generally for a longitudinal axis of arbitrary inclination, from which the relation between the expressions for the fundamental equation with respect to any longitudinal axis inclination such as parallel to the surface, parallel to the base or horizontal, is readily
discerned.

An expression for the longitudinal strain-rate is derived to obtain the flow law from longitudinal stress and strain-rate measurements. A single "generalized viscosity function" is introduced to avoid the complication of both the power flow-law parameters varying with stress.
\end{abstract}

RÉsumé. The French résumé will be found on p. 27.

Zusammenfassung. Die Gradienten der Längsspannung und der Deformationsgeschwindigkeit in Eismassen. Die Fundamentalgleichung für den Gradienten der Längsspannung und der Deformationsgeschwindigkeit von Eismassen mit geringer Oberflächenneigung (Budd, 1968) wurde von Nye (1969) exakt für jede Neigung abgeleitet. Nye zeigt, dass bei Verwendung einer veränderlichen Inklination der Längsachse, parallel zur Oberfläche, diese Gleichung ihre einfachste Form annimmt. Dennoch ist es notwendig, bei der Integration dieser Gleichung entlang der Eismasse zur Ermittlung der Spannung und Deformationsgeschwindigkeit eine feste Achsrichtung einzuführen. Hier wird die Gleichung generell für eine Längsachse von beliebiger Inklination aufgestellt, woraus die Beziehung zwischen den Ausdrücken für die Fundamentalgleichung mit Rücksicht auf irgendeine Achsneigung, wie etwa parallel zur Oberfläche, parallel zum Untergrund oder
horizontal, leicht hergeleitet werden kann.

Ein Ausdruck für die Längsdeformationsgeschwindigkeit wird abgeleitet, um die aus dem Fliessgesetz folgende Beziehung aus Messungen der Längsspannung und der Deformationsgeschwindigkeit zu erhalten. Eine einzelne "generalisierte Viskositätsfunktion" wird eingeführt, um der Komplikation der beiden Parameter des exponentiellen Fliessgesetzes, die sich mit der Spannung ändern, zu begegnen.

\section{INTRODUCTION}

Equations for the longitudinal stress and strain-rate in ice masses have been discussed by many authors including Shumskiy ( I 96 I , I963, I 967 ), Lliboutry ( 1964-65, Tom. 2, p. 631-40), Robin (1967), Budd (1968, r969), Collins (1968), and Nye (1969). Robin (1967) showed that from measured ice thickness and accumulation profiles and an assumed flow law of ice, steady state longitudinal strain-rates, stresses and surface slopes can be calculated which are in agreement with the measured surface-slope variations. Budd (I968) showed how measurements of surface strain-rate and ice surface and bedrock profiles may be used to determine the ice flow-law parameters. Furthermore it was shown that the longitudinal strain-rate gradient varied with deviations of the local surface slope. Collins (1968) used a system with horizontal and vertical axes to derive an exact equation for the longitudinal stress deviator to examine the conditions under which Robin's result applied.

The present study arises from a valuable discussion with Dr Nye who examined the approximations used in the author's original theory and showed (Nye, 1969) that an exact formulation of the equation for the longitudinal stress deviator gradient is simplified by referring the components to a longitudinal axis inclined parallel to the surface. However, since the surface slope varies along the ice mass, several difficulties arise with such an expression. To integrate this equation along the ice mass it is necessary, if curvilinear coordinates are to be avoided, that a system with fixed axes be taken. It is also necessary to take the surface and base coordinates variable along the ice mass. In some contexts it is required to know the components of the stress deviator and strain-rate with respect to axes in other directions such as parallel to the bed, or horizontal and vertical. Hence the following approach aims at 
deriving the equation for the longitudinal stress deviator gradient as generally as possible for two dimensions with respect to orthogonal axes $(x, z)$, fixed in space but with arbitrary orientation.

2. DERIVATION OF LONGITUDINAL STRESS DEVIATOR GRADIENT WITH RESPECT TO A LONGITUDINAL AXIS OF ARBITRARY INCLINATION

\subsection{Integration of the equations of motion}

Two-dimensional motion or "plane strain-rate" only is considered.

We adopt a right-hand orthogonal system of axes, $x, z$ such that the horizontal is inclined at an arbitrary angle $\chi$ to the positive $x$ direction. All angles will be taken positive for an anticlockwise rotation from the $x$-axis (see Fig. I).

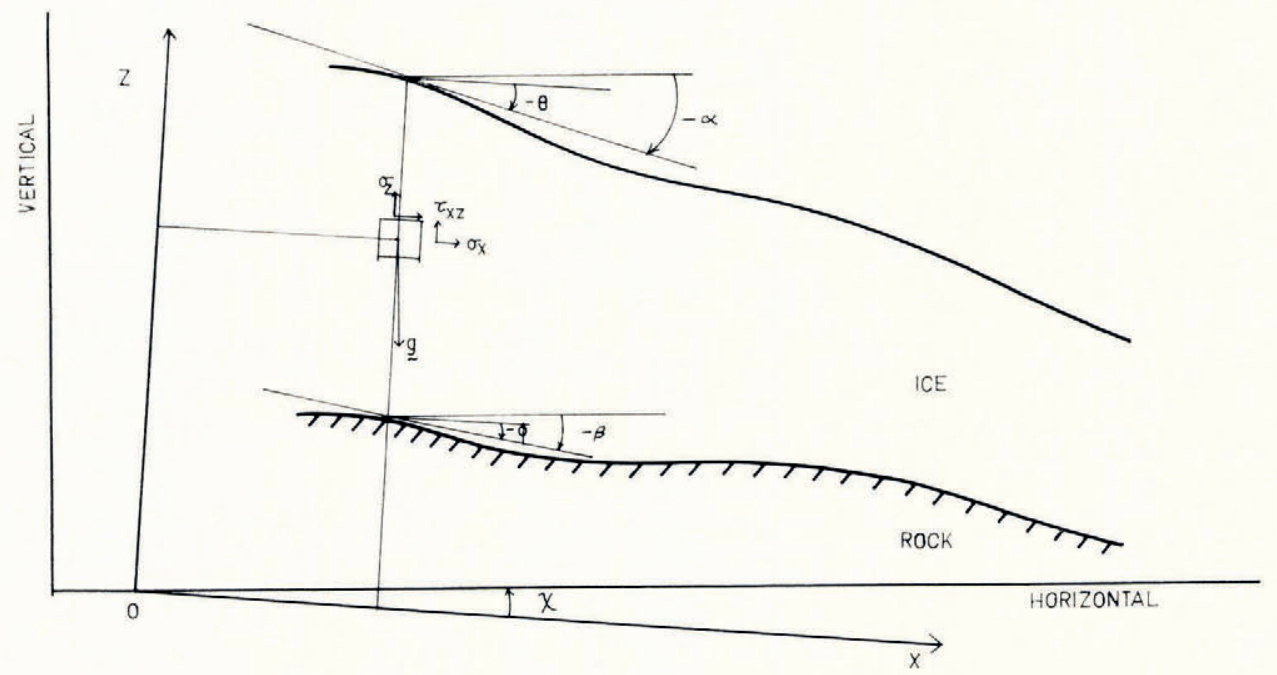

Fig. I. Coordinate system and definition of quantities.

Let $-\alpha$ be the surface slope of the ice mass at position $x,-\beta$ be the basal slope of the ice mass at position $x, z_{1}$ be the ordinate of the surface at position $x, z_{2}$ be the ordinate of the base at position $x$, write $z=z_{1}-z_{2}$ for the ice thickness at $x$ and $-\theta=-\alpha+\chi$. $-\phi=-\beta+\chi$, for the slopes of the surface and base with respect to the $x$-axis. The stress components at $(x, z)$ are denoted by $\left(\sigma_{x}, \tau_{x z} \sigma_{z}\right)$. We consider an ice mass of constant density $\rho$. Let $g$ be the gravitational acceleration, and write $g_{x}=+g \sin \chi, g_{z}=-g \cos \chi$ for its components in the directions of the axes.

The equations of equilibrium for slow steady motion may then be written as

$$
\begin{aligned}
& \frac{\partial \sigma_{x}}{\partial x}+\frac{\partial \tau_{x z}}{\partial z}+\rho g_{x}=0, \\
& \frac{\partial \sigma_{z}}{\partial z}+\frac{\partial \tau_{x z}}{\partial x}+\rho g_{z}=0 .
\end{aligned}
$$

These equations are true everywhere in the ice mass for any such system of axes so defined.

We require an expression for the longitudinal stress deviator $\sigma_{x}^{\prime}=\frac{1}{2}\left(\sigma_{x}-\sigma_{z}\right)$. Hence we differentiate Equation (I) with respect to $z$ and Equation (2) with respect to $x$ and subtract to yield

$$
\frac{\partial^{2}\left(\sigma_{x}-\sigma_{z}\right)}{\partial x \partial z}=\frac{\hat{\partial}^{2} \tau_{x z}}{\partial x^{2}}-\frac{\hat{c}^{2} \tau_{x z}}{\hat{c} z^{2}} .
$$


This equation also does not depend on the choice of the axis orientation. It is only when this equation is integrated that it becomes necessary to specify the boundary conditions in terms of the axis direction.

We integrate Equation (3) with respect to $z$ from $z$, to $z$

$$
\left.\left.\left.\frac{\hat{c}\left(\sigma_{x}-\sigma_{z}\right)}{\partial x}=-\frac{\partial \sigma_{z}}{\partial x}\right)_{z_{1}}+\frac{\partial \sigma_{x}}{\partial x}\right)_{z_{1}}+\frac{\hat{\partial} \tau_{x z}}{\partial z}\right)_{z_{1}}-\frac{\partial \tau_{x z}}{\partial z}+\int_{z_{1}}^{z} \frac{\partial^{2} \tau_{x z}}{\partial x^{2}} \mathrm{~d} z .
$$

From Equation (1) we note at the surface that

$$
\left.\left.\frac{\partial \sigma_{x}}{\partial x}\right)_{z_{1}}+\frac{\partial \tau_{x z}}{\partial z}\right)_{z_{1}}=-\rho g x
$$

Hence, using this, Equation (4) may be written

$$
\left.\frac{\partial\left(\sigma_{x}-\sigma_{z}\right)}{\partial x}=-\rho g x-\frac{\partial \sigma_{z}}{\partial x}\right)_{z_{1}}-\frac{\partial \tau_{x z}}{\partial z}+\int_{z_{1}}^{z} \frac{\partial^{2} \tau_{x z}}{\partial x^{2}} \mathrm{~d} z
$$

Now integrating again with respect to $z$, this time from $z_{1}$ to $z_{2}$, noting the first two terms on the right are constant with $z$ and also $z=z_{1}-z_{2}$, gives

$$
\left.\int_{z_{1}}^{z_{1}} \frac{\partial\left(\sigma_{x}-\sigma_{z}\right)}{\partial x} \mathrm{~d} z=\rho g_{x} z+z \frac{\partial \sigma_{z}}{\partial x}\right)_{z_{1}}-\tau_{x z_{2}}+\tau_{x z_{1}}+\int_{z_{1}}^{z_{1}} \int_{z_{1}}^{z} \frac{\partial^{2} \tau_{x z}}{\partial x^{2}} \mathrm{~d} z \mathrm{~d} z .
$$

This equation is exact and expresses the mean longitudinal stress deviator gradient in terms of the boundary conditions at the surface and base of a column of ice. We shall shortly examine the surface and base boundary conditions in detail. But first it is often required to integrate this equation with respect to $x$. To do this we note that the left-hand side may be written

$$
\int_{z_{1}}^{z_{2}} \frac{\hat{c}\left(\sigma_{x}-\sigma_{z}\right)}{\partial x} \mathrm{~d} z=\frac{\partial \int_{z_{1}}^{z z}\left(\sigma_{x}-\sigma_{z}\right) \mathrm{d} z}{\partial x}-\left(\sigma_{x}-\sigma_{z}\right) z_{z} \frac{\partial z_{2}}{\partial x}+\left(\sigma_{x}-\sigma_{z}\right) z_{1} \frac{\partial z_{1}}{\partial x} .
$$

\subsection{Boundary conditions}

At the surface we make the assumption that the shear stress parallel to the surface is zero, and that the normal stress is the atmospheric pressure $p$.

If $\theta$ is the angle between the $x$-axis and the surface, then using the standard formula for the rotation of axes, the normal and shear stresses are related to the components in the $x, z$ directions at the surface by (cf. e.g. Jaeger ( 1962$)$ )

$$
\begin{gathered}
-p=\sigma_{x} \sin ^{2} \theta-2 \tau_{x z} \sin \theta \cos \theta+\sigma_{z} \cos ^{2} \theta, \\
0=\left(\sigma_{x}-\sigma_{z}\right) \sin \theta \cos \theta+\tau_{x z}\left(\sin ^{2} \theta-\cos ^{2} \theta\right) .
\end{gathered}
$$

Ior Equation (8) we require only Equation (IO) in the form (dividing by $\cos ^{2} \theta$ )

$$
\left(\sigma_{x}-\sigma_{z}\right) z_{\mathrm{r}} \tan \theta=\tau_{x z_{\mathrm{r}}}\left(\mathrm{I}-\tan ^{2} \theta\right) .
$$

Similarly at the base, if $-\tau_{\mathrm{b}}$ is the basal shear stress parallel to the bed, where $-\phi$ is the angle between the base and the $x$-axis, then

$$
-\tau_{\mathrm{b}}=-\left(\sigma_{x}-\sigma_{z}\right) \sin \phi \cos \phi+\tau_{x z}\left(\cos ^{2} \phi-\sin ^{2} \phi\right)
$$

and therefore

$$
-\left(\sigma_{x}-\sigma_{z}\right)_{z_{2}} \tan \phi=-\tau_{x z_{2}}\left(\mathrm{I}-\tan ^{2} \phi\right)-\frac{\tau_{\mathrm{b}}}{\cos ^{2} \phi}
$$


Since $\frac{\partial z_{2}}{\partial x}=\tan \phi$ and $\frac{\partial z_{1}}{\partial x}=\tan \theta$, using Equations (II), (I2) and (8) in Equation (7) and writing $-Z\left(\bar{\sigma}_{x}-\bar{\sigma}_{z}\right)$ for $\int_{z_{1}}^{z_{z}}\left(\sigma_{x}-\sigma_{z}\right) \mathrm{d} z$, $\left.-\frac{\partial Z\left(\bar{\sigma}_{x}-\bar{\sigma}_{z}\right)}{\partial x}=\rho g x z+z \frac{\partial \sigma_{z}}{\partial x}\right)_{z_{1}}-\tau_{x z_{2}} \tan ^{2} \phi-\tau_{x z_{1}} \tan ^{2} \theta+\frac{\tau_{\mathrm{b}}}{\cos ^{2} \phi}+\int_{z_{\mathrm{t}}}^{z_{2}} \int_{z_{\mathrm{1}}}^{z} \frac{\partial^{2} \tau_{x z}}{\partial x^{2}} \mathrm{~d} z \mathrm{~d} z . \quad$

The term $\left.\frac{\partial \sigma_{z}}{\partial x}\right)_{z_{1}}$ is zero for points where the surface is parallel to the $x$-axis. For other slopes however this term depends on the longitudinal stress and stress-gradients and the curvature of the surface. We now evaluate this term in full to show under what conditions it may be approximated by $\rho g_{z} \tan \theta$.

If $s$ denotes the distance along the curved surface,

$$
\frac{\partial \sigma_{z}}{\partial x}=-\frac{\partial \sigma_{z}}{\partial z} \tan \theta+\frac{\partial \sigma_{z}}{\partial s} \frac{\mathrm{I}}{\cos \theta} .
$$

Using Equation (2) this may be written

$$
\frac{\partial \sigma_{z}}{\partial x}=+\rho g_{z} \tan \theta+\frac{\partial \tau_{x z}}{\partial x} \tan \theta+\frac{\partial \sigma_{z}}{\partial s} \frac{\mathrm{I}}{\cos \theta} .
$$

Similarly expanding $\partial \tau_{x z} / \partial x$ and using Equation (I) gives

$$
\begin{aligned}
& \frac{\partial \sigma_{z}}{\partial x}=+\rho g_{z} \tan \theta+\frac{\partial \tau_{x z}}{\partial z} \tan ^{2} \theta+\frac{\partial \tau_{x z}}{\partial s} \frac{\sin \theta}{\cos ^{2} \theta}+\frac{\partial \sigma_{z}}{\partial s} \frac{\mathrm{I}}{\cos \theta} \\
= & \rho g_{z} \tan \theta-\frac{\partial \sigma_{x}}{\partial x} \tan ^{2} \theta-\rho g_{x} \tan ^{2} \theta+\frac{\partial \tau_{x z}}{\partial s} \frac{\sin \theta}{\cos ^{2} \theta}+\frac{\partial \sigma_{z}}{\partial s} \frac{\mathrm{I}}{\cos \theta} .
\end{aligned}
$$

Now at the surface if $\sigma_{\mathrm{n}}, \sigma_{1}$ are the normal and longitudinal stresses and $\sigma_{1}^{\prime}=\frac{1}{2}\left(\sigma_{1}-\sigma_{\mathrm{n}}\right)$

$$
\tau_{x z}=\sigma_{1}^{\prime} \sin 2 \theta \quad \text { and } \quad \sigma_{z}=\sigma_{\mathrm{n}} \cos ^{2} \theta+\sigma_{1}^{\prime} \sin ^{2} \theta .
$$

Hence

$$
\frac{\partial \tau_{x z}}{\partial s}=\frac{\partial \sigma_{1}^{\prime}}{\partial s} \sin 2 \theta+\sigma_{1}^{\prime} 2 \cos 2 \theta \frac{\partial \theta}{\partial s}
$$

and

$$
\frac{\partial \sigma_{z}}{\partial s}=-\sigma_{\mathrm{n}} 2 \cos \theta \sin \theta \frac{\partial \theta}{\partial s}+\frac{\partial \sigma_{1}}{\partial s} \sin ^{2} \theta+\sigma_{1} 2 \sin \theta \cos \theta \frac{\partial \theta}{\partial s} .
$$

Substituting in Equation (I5) and taking surface values

$$
\begin{aligned}
\left.\frac{\partial \sigma_{z}}{\partial x}\right)_{z_{1}} & \left.=\rho g_{z} \tan \theta-\frac{\partial \sigma_{x}}{\partial x}\right)_{z_{x}} \tan ^{2} \theta-\rho g_{x} \tan ^{2} \theta+\frac{\partial \sigma_{1}^{\prime}}{\partial s} 2 \sin \theta \tan \theta+ \\
& +\sigma_{1}^{\prime} 2 \cos 2 \theta \tan \theta \frac{\partial \theta}{\partial x}-\sigma_{\mathrm{n}} \sin 2 \theta \frac{\partial \theta}{\partial s}+\frac{\partial \sigma_{1}}{\partial s} \sin \theta \tan \theta+\sigma_{1} \sin 2 \theta \frac{\partial \theta}{\partial x} .
\end{aligned}
$$

Hence to take as the first approximation

$$
\left.\frac{\partial \sigma_{z}}{\partial x}\right)_{z_{\mathrm{t}}} \approx \rho g_{z} \tan \theta
$$

it is necessary (and sufficient provided the longitudinal stress and stress gradients are not too large) that not only the slope $\theta$ be small but also the slope gradient, i.e. $\frac{\mathrm{I}}{\theta} \frac{\partial \theta}{\partial s} \approx \frac{\mathrm{I}}{\sigma_{1}} \frac{\partial \sigma_{1}}{\partial s}$ or less. Since the longitudinal stresses vary with the surface slope this is usually the case. However abrupt changes of surface slope or stress (e.g. surface crevasses) will not be covered by the approximate formula. 
Finally substituting Equation ( 16 ) in Equation (13) and writing the components of $\mathbf{g}$ in full gives

$$
\begin{gathered}
\left.-\frac{\partial Z\left(\bar{\sigma}_{x}-\bar{\sigma}_{z}\right)}{\partial x}=\rho g Z \sin \chi-\rho g Z \cos \chi \tan \theta-Z \frac{\partial \sigma_{x}}{\partial x}\right)_{z_{1}} \tan ^{2} \theta- \\
-\rho g Z \sin \chi \tan ^{2} \theta+Z \frac{\partial \sigma_{1}^{\prime}}{\partial s} 2 \sin \theta \tan \theta+\sigma_{1}^{\prime} Z 2 \cos 2 \theta \tan \theta \frac{\partial \theta}{\partial x}-Z \sigma_{\mathrm{n}} \sin 2 \theta \frac{\partial \theta}{\partial s}+ \\
+z \frac{\partial \sigma_{1}}{\partial s} \sin \theta \tan \theta+\sigma_{1} z \sin 2 \theta \frac{\partial \theta}{\partial x}-\tau_{x z_{2}} \tan ^{2} \phi+\tau_{x z_{1}} \tan ^{2} \theta+\frac{\tau_{\mathrm{b}}}{\cos ^{2} \phi}+\int_{z_{1}}^{z_{2}} \int_{z=}^{z} \frac{\partial^{2} \tau_{x z}}{\partial x^{2}} \mathrm{~d} z \mathrm{~d} z .
\end{gathered}
$$

This equation is exact, it has arbitrary orientation $\chi$ for the $x$-axis, and applies everywhere along the ice mass with the same rectilinear coordinates, and hence it may be directly integrated with respect to $x$, without resorting to curvilinear coordinates. From this equation the conditions required for various simplified forms may be determined.

\subsection{Special cases of longitudinal axis inclination}

(1) Small slopes.

For small slopes $\chi, \theta, \phi$ and slope gradients (i.e. neglecting second and higher orders), all except the first two and last two terms on the right of Equation (1 7 ) are negligible so that it reduces to the form given by Budd (1968)

$$
\frac{\partial \bar{\sigma}_{x}^{\prime}}{\partial x}=\frac{1}{2}\left[\rho g Z(\alpha-f)-\iint \frac{\partial^{2} \tau_{x z}}{\partial x^{2}} \mathrm{~d} z \mathrm{~d} z\right]
$$

where $\bar{\sigma}_{x}^{\prime}=\frac{1}{2}\left(\bar{\sigma}_{x}-\bar{\sigma}_{z}\right), f=\tau_{\mathrm{b}} / \rho g Z, \alpha=\theta-\chi$. In this case only the surface slope is relevant and it is therefore immaterial whether the axes are taken horizontal, parallel to the surface or parallel to the base. The senses of the signs in Equation (18) are such that an increasing tension in the direction of motion is required to balance either a smaller negative slope (downwards in the direction of motion) or a greater basal stress against the direction of motion.

Other simplified forms of Equation ( 17 ) may be readily obtained by choosing the longitudinal axis horizontal $(\chi=0)$, parallel to the surface $(\theta=0, \chi=\alpha)$, or parallel to the base $(\phi=0, \chi=\beta)$, at some particular position.

(2) For the longitudinal axis $x$ parallel to the surface at some position we have $\chi=\alpha$, $\theta=0, \phi=\alpha-\beta$, and Equation (17) reduces to

$$
\frac{\partial Z\left(\bar{\sigma}_{x}-\bar{\sigma}_{z}\right)}{\partial x}=\rho g Z \sin \alpha-\tau_{x z_{2}} \tan ^{2}(\alpha-\beta)+\frac{\tau_{\mathrm{b}}}{\cos ^{2} \phi}+\iint \frac{\partial^{2} \tau_{x z}}{\partial x^{2}} \mathrm{~d} z \mathrm{~d} z .
$$

An alternative form may be obtained directly from Equation (7)

$$
\int_{z}^{z_{2}} \frac{\partial\left(\sigma_{x}-\sigma_{z}\right)}{\partial x} \mathrm{~d} z=\rho g z \sin \alpha-\tau_{x z_{2}}+\iint \frac{\partial^{2} \tau_{x z}}{\partial x^{2}} \mathrm{~d} z \mathrm{~d} z .
$$

These results correspond to the form derived by Nye (1969) except that here $Z$ is not necessarily constant, and the no-slip condition at the base is not required (i.e. $\left(\sigma_{x}-\sigma_{z}\right)$ is not necessarily zero, and $\tau_{\mathrm{b}}$ is given in general by Equation (12)).

For small $(\alpha-\beta)$ these results all reduce to Equation (18) above. However, since the $x$-axis here is parallel to the surface, whose slope varies along the ice mass, this equation cannot be readily integrated with respect to $x$ without resort to curvilinear coordinates.

(3) For the $x$-axis parallel to the base, $x=\beta, \phi=0, \theta=\alpha-\beta$. Equation (17) becomes, for small $(\alpha-\beta)$, 


$$
\begin{aligned}
& \frac{2 \partial Z \bar{\sigma}_{x}^{\prime}}{\partial x}=\rho g z \sin \beta-\rho g z \cos \beta \tan (\alpha-\beta)+\rho g z \sin \beta \tan ^{2}(\alpha-\beta)+ \\
& \left.\quad+Z \frac{\partial \sigma_{x}}{\partial x}\right)_{z_{1}} \tan ^{2}(\alpha-\beta)+\tau_{x z_{1}} \tan ^{2}(\alpha-\beta)+\tau_{\mathrm{b}}+\int_{z_{1}}^{z_{2}} \int_{z_{1}}^{z} \frac{\partial^{2} \tau_{x z}}{\partial x^{2}} \mathrm{~d} z \mathrm{~d} z .
\end{aligned}
$$

For both small $(\alpha-\beta)$ and $\beta$ this immediately reduces to the form of Equation (18). This equation is also useful in the case of small $(\alpha-\beta)$ but moderate values of $\beta$ and if the $x$-axis is chosen parallel to the average basal slope over the length, then it may be readily integrated with respect to $x$.

(4) For the $x$-axis horizontal $\chi=0, \theta=\alpha, \phi=\beta$. This form may be useful for considering a wedge-type profile say near a terminus, with small $\beta$ and $\partial \alpha / \partial x$ but moderate $\alpha$. In this case if the longitudinal surface stress and slope gradients are not large Equation (17) reduces to

$$
\frac{2 \partial \bar{\sigma}_{x}^{\prime}}{\partial x}=\rho g z \tan \theta+Z \frac{\partial \sigma_{1}}{\partial s} \sin \theta \tan \theta+\tau_{x z_{1}} \tan ^{2} \theta+\tau_{\mathbf{b}}+\iint \frac{\partial^{2} \tau_{x z}}{\partial x^{2}} \mathrm{~d} z \mathrm{~d} z .
$$

Again even for moderate $\theta$ this equation differs only slightly from Equation (18).

\section{Application to the study of longitudinal strain-rates}

\subsection{Preliminary comments}

The theory so far, for stresses, is exact and applies generally (for slow creep) whatever the flow law. The application of this equation to the study of flow properties of ice masses from elevation and bedrock profiles and surface strain-rates, requires some additional less substantiated assumptions.

Before examining the flow law, it is necessary to make a comment concerning the second term on the right of Equation ( 18 ) viz.

$$
T=\iint \frac{\partial^{2} \tau_{x z}}{\partial x^{2}} \mathrm{~d} z \mathrm{~d} z
$$

This term will be discussed in a separate paper concerning ice flow over undulations (Budd, 1970), but it has already been indicated (Budd, I968, I969) that $T$ is important for small wavelength undulations $(\lambda \approx 3 Z)$. $T$ is zero for $\gamma_{x z}$ constant or increasing linearly with $x$, but for flow over undulations it enhances the relative maximum extension on crests and compression in troughs, such that Equation (18) may be written

$$
\frac{\partial Z \bar{\sigma}_{x}^{\prime}}{\partial x}=\frac{1}{2} \rho g Z k \delta \alpha
$$

where $\delta \alpha=\alpha_{\mathrm{s}}-\bar{\alpha}, k \simeq \mathrm{I}+\frac{4 \pi^{2}}{3}\left(\frac{Z}{\lambda}\right)^{2} \rightarrow \mathrm{I}$ for long waves, $\alpha_{\mathrm{S}}$ is the local surface slope and $\bar{\alpha}$ is the mean slope over $c$. Io to $20 Z$.

The assumption of replacing $\tau_{\mathrm{b}}$ by $\rho g Z \bar{\alpha}$ is largely empirical (cf. Budd, Ig68) but it is a good approximation provided $\bar{\alpha}$ is calculated over such a distance that the longitudinal stress is unimportant $(x>c$. 10Z). Several earlier workers (Robin, I967; Budd, I968; Collins, I968) have used a power law for flow, say

$$
\dot{\epsilon}_{x}=\left(\frac{\sigma_{x}^{\prime}}{B}\right)^{n}
$$

and replaced $\sigma_{x}^{\prime}$ in Equation $(\mathrm{I} 8)$ by $B \dot{\epsilon}_{x^{\mathrm{I}}} / n$. This is in many instances unsatisfactory since it neglects the effect of the vertical shear. The question arises: is the longitudinal strain-rate much higher in regions of high vertical shear for the same values of longitudinal stress deviator 
and ice temperatures? For Newtonian flow it would not be, but for a high power law for flow it would be.

The following analysis aims at devising a method to answer questions such as this by determining the flow law from measurements of longitudinal stress and strain-rates in regions with differing degrees of vertical shear.

\subsection{Derivation of the flow law of ice from the longitudinal stress and strain-rate gradients}

To convert the equation for longitudinal stress gradient to an equation in strain-rate gradient it is necessary to re-examine the flow law of ice.

With a power law for flow it is only satisfactory to replace $\bar{\sigma}_{x}^{\prime}$ by $B \bar{\epsilon}_{x}^{\mathrm{I} / n}$ if $\tau_{x z} \ll \frac{1}{2}\left(\sigma_{x}-\sigma_{z}\right)$ or if $n \approx \mathrm{I}$. In practice (McLaren, ${ }^{1968)} \tau_{x z}$ is often much larger than $\bar{\sigma}_{x}^{\prime}$. The major problem then is to consider the relation between $\bar{\sigma}_{x}^{\prime}$ and $\bar{\epsilon}_{x}$ when $\tau_{x z}$ is not necessarily small.

We abandon the power-law formulation of the stress-strain-rate relation for ice

$$
\dot{\epsilon}_{i j}=\frac{|\tau|^{n-1}}{B^{n}} \sigma_{i j}
$$

where $\sigma_{i j}^{\prime}$ is the stress deviator and $\tau$ the octahedral shear stress, since $n$ and $B$ are both found to vary with stress. Instead we adopt a single-parameter "generalized viscosity" relationship of the form

$$
\dot{\epsilon}_{i j}=\frac{\mathrm{I}}{\eta} \sigma_{i j}^{\prime}
$$

where $\eta(\tau, \theta)$ is a function of both stress and temperature.

For the octahedral shear values of stress $\tau$, and strain-rate $\dot{\epsilon}$, Equation (24) gives (cf. Nye, 1953)

$$
\dot{\epsilon}=\frac{1}{\eta} \tau
$$

Hence

$$
\eta=\frac{\tau}{\dot{\epsilon}}
$$

This may be regarded as an alternative definition of $\eta$. Equation (25) may be regarded as the flow law of ice, and for each constant temperature represents a single curve on the $\dot{\epsilon}$ versus $\tau$ diagram. It is these curves we wish to determine. The important result is that for a given stress state the longitudinal stress and strain-rate have the same ratio as the octahedral values.

So, substituting for the average longitudinal stress deviator through the ice column $\bar{\sigma}_{x}^{\prime}=\overline{\eta \dot{\epsilon} x}$ in the equation for stress gradient (18)

we obtain

$$
\frac{\partial \bar{\sigma}_{x}^{\prime}}{\partial x}=\frac{1}{2} \rho g(\alpha-f)-\frac{1}{2} \frac{\partial^{2} \int \hat{\int} \tau_{x z} \mathrm{~d} z \mathrm{~d} z}{\partial x^{2}},
$$

or

$$
\begin{aligned}
\frac{\partial \overline{\eta \dot{\epsilon} x}}{\hat{\partial x}}= & \frac{1}{2} \rho g(\alpha-f)-\frac{1}{2} \frac{\partial^{2} \iint \tau_{x z} \mathrm{~d} z \mathrm{~d} z}{\partial x^{2}} \\
\equiv & \frac{1}{2} \rho g k \delta \alpha^{\star} \quad\left(\text { as a definition of } k \delta \alpha^{\star}, \text { cf. section } 3 \cdot \mathrm{I}\right) \\
& \left.\quad \overline{\eta \dot{\dot{\epsilon}_{x}}}\right|_{x_{1}} ^{x}=\frac{1}{2} \rho g k \int_{x_{1}}^{x} \delta \alpha^{\star} \mathrm{d} x .
\end{aligned}
$$

We now define a weighted mean flow parameter $\eta^{\star}$ through a vertical column by

$$
\eta^{\star}=\frac{\overline{\eta \dot{\epsilon}}}{\overline{\bar{\epsilon}}}
$$


Then by integrating Equation $\left(3^{\circ}\right)$ (for fluctuations around a mean value, i.e. taking $\dot{\epsilon}_{x_{1}}=0$ for $\delta \alpha^{\star}=0$ )

or

$$
\overline{\bar{\epsilon}}_{x_{1}}=\frac{\rho g k}{2 \eta^{\star}} \int \delta \alpha^{\star} \mathrm{d} x
$$

where

$$
\overline{\dot{\epsilon}}_{x}=\frac{\mathrm{I}}{\eta^{\star}} \bar{\sigma}_{x}^{\prime}
$$

$$
\bar{\sigma}_{x}^{\prime}=\frac{1}{2} \rho g k \int \delta \alpha^{\star} \mathrm{d} x .
$$

Hence from the ratio of the longitudinal stress deviator $\bar{\sigma}_{x}^{\prime}$ to the longitudinal strain-rate $\overline{\boldsymbol{\epsilon}}_{x}$ we obtain $\eta^{\star}$ for that $\tau$ and $\theta$. We now use these values of $\eta^{\star}$ and $\tau$ to determine the flow law in terms of octahedral values.

Since in terms of the octahedral values $\eta^{\star}=\bar{\tau} / \overline{\dot{\epsilon}}$ we can now obtain the flow law of ice by calculating $\overline{\dot{\epsilon}}$ from $\eta^{\star}$ and $\bar{\tau}$ for each value and illustrate this by then plotting $\overline{\dot{\epsilon}}$ against $\bar{\tau}$.

For two-dimensional flow the octahedral shear stress $\bar{\tau}$ is calculated from

$$
\tilde{\tau}=\overline{\left(\tau_{x z}^{2}+\sigma_{x}^{\prime 2}\right)^{1 / 2}} \approx\left(\bar{\tau}_{x z}^{2}+\bar{\sigma}_{x}^{\prime 2}\right)^{\mathrm{I} / 2}
$$

taking

$$
\bar{\tau}_{x z}=\frac{1}{2} \rho g \bar{\alpha} Z \quad \text { and } \quad \bar{\sigma}_{x}^{\prime}=\frac{1}{2} \rho g k \int \delta \alpha^{\star} \mathrm{d} x .
$$

Here $\bar{\alpha}$ is taken as the mean surface slope over a distance $x$ about ten times the ice thickness. The approximation in Equation (34) is expected to be close since $\tau_{x z}$ increases linearly with depth and $\bar{\sigma}_{x}^{\prime}$ only varies slightly in the upper layers.

These values of stress are derived directly from the measured elevation and ice thickness profiles. The surface strain rate $\dot{\epsilon}_{\mathrm{S}}$ can be measured, but to obtain the average strain-rate through the column something must be known about the ratio $\dot{\epsilon}_{\mathrm{s}} / \bar{\epsilon}_{x}=\lambda$ say.

This normally requires information on the velocity-depth profile. However if the ice is not slipping at the base then we may expect the strain-rates to vary with depth in a similar way to the velocity $V$, i.e.

$$
\frac{\dot{\epsilon}_{\mathrm{s}}}{\overline{\dot{\epsilon}}_{x}}=\frac{V_{\mathrm{s}}}{V_{x}}=\lambda
$$

For cold ice caps the velocity profile depends on the temperature profile and estimates can be calculated (cf. Budd, ig69).

In the absence of a velocity profile the value of $\lambda$ can be assumed to lie between $\frac{2}{3}$ (for viscous flow with no slip) and I (for block sliding) being near $90 \%$ for typical ice cap temperature profiles. In terms of the measured surface strain-rates, then, we may write

$$
\dot{\epsilon}_{\mathrm{s}}=\frac{\rho g k}{2 \eta^{\star} \lambda} \int \delta \alpha^{\star} \mathrm{d} x \quad \text { or } \quad \eta^{\star}=\frac{\bar{\sigma}_{x}^{\prime}}{\lambda \dot{\epsilon}_{\mathrm{s}}}
$$

From the measured variations in surface strain rates $\dot{\epsilon}_{\mathrm{s}}$, and surface slope $\alpha$, the generalized viscosity $\eta^{\star}(\bar{\tau}, \bar{\theta})$ can be determined from Equation (37) and then using the values of mean octahedral shear stress from Equations (34) and (35), and for the mean temperature for the column at that position, a point on the stress-strain-rate relationship $\dot{\epsilon}(\bar{\tau}, \bar{\theta})$ can be established by plotting

versus $\bar{\tau}$.

$$
\overline{\dot{\epsilon}}=\lambda \epsilon_{\mathrm{s}} \bar{\tau} / \bar{\sigma}_{x}^{\prime}
$$

Strictly $\eta^{\star}(\bar{\tau}, \bar{\theta})$ is not a unique single-valued function of $\bar{\tau}$ and $\bar{\theta}$ because it depends not only on the mean values but also on the vertical distributions of $\theta$ and $\tau$. However until more is known about the vertical distribution of longitudinal strain-rate this method provides a useful means of analysing measured surface longitudinal strain-rates in regions of different mean temperature and stress. 
To obtain the complete set of curves for $\dot{\epsilon}(\bar{\tau}, \bar{\theta})$, many values of $\dot{\epsilon}_{\mathrm{S}}$ covering a wide range of shear stress $\bar{\tau}$ and temperature $\bar{\theta}$ are required. For a typical cold ice cap the ice temperature $\tilde{\theta}$ and the shear stress $\bar{\tau}$ both generally increase from the inland towards the coast and hence each contribute to higher I $/ \eta^{\star}$ values (i.e. $\overline{\dot{\epsilon}}_{x} / \bar{\sigma}_{x}^{\prime}$ ratios) near the coast. For temperate ice masses (at pressure melting point throughout) we may expect the variations in the ratio of the longitudinal strain-rate to longitudinal stress to depend just on the variations in the magnitude of the octahedral shear stress.

\section{AckNowledgements}

The author is indebted to Dr J. F. Nye of the University of Bristol for his constructive criticism of the author's earlier work, and the emphasis on rigour for an exact treatment of this problem. Dr. Nye also provided the author with an early copy of his i 969 paper prior to publication. Dr W. S. B. Paterson of the Polar Continental Shelf Project, Ottawa also provided some helpful comments on the earlier work. The author is grateful to Dr U. Radok of the University of Melbourne for critically reviewing the present manuscript.

MS. received 8 fuly 1969 and in revised form 23 September 1969. Substantial proof revisions received 8 January 1970

\section{REFERENCES}

Budd, W. F. 1968. The longitudinal velocity profile of large ice masses. Union de Géodésie et Géophysique Internationale. Association Internationale d'Hydrologie Scientifique. Assemblée générale de Berne, 25 sept.-7 oct. I967. [Commission de Neiges et Glaces.] Rapports et discussions, p. 58-77.

Budd, W. F. r 969 . The dynamics of ice masses. ANARE Scientific Reports. Ser. A(IV). Glaciology. Publication No. 108.

Budd, W. F. 1970. Ice flow over bedrock perturbations. Journal of Glaciology, Vol. 9, No. 55, p. $29-48$.

Collins, I. F. I968. On the use of the equilibrium equations and flow law in relating surface and bed topography of glaciers and ice sheets. Fournal of Glaciology, Vol. 7, No. 50, p. 199-204.

Jaeger, J. C. 1962. Elasticity, fracture and flow; with engineering and geological applications. Second edition. London, Methuen. (Monographs on Physical Subjects.)

Lliboutry, L. 1964-65. Traité de glaciologie. Paris, Masson et Cie. 2 vols.

McLaren, W. A. r 968 . A study of the local ice cap near Wilkes, Antarctica. ANARE Scientific Reports. Ser. A(IV). Glaciology. Publication No. ro3.

Nye, J. F. 1953. The flow law of ice from measurements in glacier tunnels, laboratory experiments, and the Jungfraufirn borehole experiment. Proceedings of the Royal Society, Ser. A, Vol. 219, No. 1 1 39, p. 477-89. Nye. J. F. I 969 . The effect of longitudinal stress on the shear stress at the base of an ice sheet. Fournal of Glaciolog),
Vol. 8, No. 53, p. $207-13$.

Robin, G. de Q. 1967. Surface topography of ice sheets. Nature, Vol. 215, No. 5105, p. 1029-32.

Shumskiy, P. A. 1961. On the theory of glacier motion. Union Géodésique et Géophysique Internationale. Association Internationale d'Hydrologie Scientifique. Assemblée générale de Helsinki, 25-7 6-8 1960 . Colloque sur la glaciologie
antarctique, p. ${ }^{2} 4^{2-49}$.

Shumskiy, P. A. 1963 . On the theory of glacier variations. Bulletin de l'Association Internationale d'Hydrologie Scientifique, 8 e An., No. I, p. $45^{-5} 6$.

Shumskiy, P. A. 1967. The distribution of stress, velocity and temperature in glaciers. (In Ōura, H., ed. Physics of snow and ice: international conference on low temperature science. . . . 1966. . . Proceedings, Vol. I, Pt. I. [Sapporo], Institute of Low Temperature Science, Hokkaido University, p. $37 \mathrm{I}-84$.)

RÉSUMÉ. La contrainte longitudinale et le gradient longitudinal de vilesse de deformation dans les agglomérations de glace. L'équation fondamentale de la contrainte longitudinale et du gradient de vitesse de déformation pour des masses de glace à faible pente (Budd, I968) a été dérivée exactement pour chaque pente par Nye (I969). Ce dernier montre qu'en se servant d'un axe longitudinal d'inclinaison variable, parallèle à la surface, cette équation prend sa plus simple expression. Cependant, pour l'intégration de cette équation le long de la masse de glace pour obtenir les vitesses des contraintes et des déformations, il est nécessaire de se servir d'une direction d'axe fixe. Ici l'équation est dérivée généralement pour un axe longitudinal d'inclinaison arbitraire. de laquelle est réellement distinguée la relation entre les expressions de l'équation fondamentale en tenant compte de toute inclinaison d'axe longitudinal telle que parallèle à la surface, parallèle à la base ou horizontale. Une expression pour la vitesse de déformation longitudinale est dérivée pour obtenir la loi d'écoulement des mesures de la contrainte longitudinale et de la vitesse de déformation. Une simple fonction de viscosité généralisée est introduite pour éviter la complication à la fois des paramètres de loi d'écoulement et de sa puissance variant avec la contrainte. 